\title{
Patterns of Neural Circuit Activation and Behavior during Dominance Hierarchy Formation in Freely Behaving Crayfish
}

\author{
Jens Herberholz, Fadi A. Issa, and Donald H. Edwards \\ Department of Biology, Georgia State University, Atlanta, Georgia 30302-4010
}

Creation of a dominance hierarchy within a population of animals typically involves a period of agonistic activity in which winning and losing decide relative positions in the hierarchy. Among crayfish, fighting between size-matched animals leads to an abrupt change of behavior as the new subordinate retreats and escapes from the attacks and approaches of the dominant (Issa et al., 1999). We used high-speed videography and electrical recordings of aquarium field potentials to monitor the release of aggressive and defensive behavior, including the activation of neural circuits for four different tail-flip behaviors. We found that the sequence of tail-flip circuit excitation traced the development of their dominance hierarchy. Offensive tail flipping, attacks, and approaches by both animals were followed by a sharp rise in the frequency of nongiant and medial giant escape tail flips and a fall in the frequency of offensive tail flips of the new subordinate. These changes suggest that sudden, coordinated changes in the excitability of a set of neural circuits in one animal produce the changes in behavior that mark its transition to subordinate status.

Key words: crayfish; fighting; agonistic interaction; dominance hierarchy; social behavior; field potential; escape; command neuron; tail flip; neural circuit activation
Social dominance hierarchies are an organizing mechanism for most animal societies (Wilson, 1975) and are readily observable because of the different patterns of behavior displayed by animals of different social rank. Although the formation of social hierarchies has been studied in many species, the neural bases of the status-related differences in behavior are unknown, as are the neural mechanisms for the usually sudden change in social behavior that marks the initial formation of a hierarchical relationship.

Decapod crustaceans, especially lobsters and crayfish, provide a useful model for the study of the neural mechanisms of hierarchy formation (Kravitz, 1988). Social dominance hierarchies form readily among crayfish after a brief period of fighting (Bovbjerg, 1953; Lowe, 1956; Figler et al., 1995) and are stable over many days if the dominant animal is the largest of the group (Pavey and Fielder, 1996; Issa et al., 1999). Fighting between pairs of sizedmatched crayfish and lobsters is marked by an escalating series of behaviors leading to grappling and wrestling with the heavy claws (Bruski and Dunham, 1987; Huber and Kravitz, 1995; Krasne et al., 1997). The fighting decreases when one animal (the new subordinate) breaks off contact with its opponent (the new dominant) by escaping or retreating (Issa et al., 1999).

The often sudden change in the behavior of one animal from fighting to escaping marks the decision point at which the social hierarchy is determined. The neural mechanisms in crayfish and lobsters that underlie this decision are unknown but may involve changes in the threshold of neural circuits that mediate discrete behavior patterns displayed during agonistic interactions. Three well known circuits for tail-flip escape are obvious candidates. The lateral giant (LG) and medial giant (MG) circuits are each

\footnotetext{
Received Sept. 28, 2000; revised Dec. 22, 2000; accepted Jan. 4, 2001.

This work was supported by National Science Foundation Grant IBN 9726819.

J.H. and F.A.I. contributed equally to this work.

Correspondence should be addressed to Dr. Donald H. Edwards at the above address. E-mail: biodhe@panther.gsu.edu.

Copyright (C) 2001 Society for Neuroscience $0270-6474 / 01 / 212759-09 \$ 15.00 / 0$
}

organized around a set of giant interneurons that function as command neurons to trigger stereotyped tail-flip escapes in response to massive phasic sensory stimulation of the abdomen or cephalothorax, respectively (Edwards et al., 1999). A set of nongiant (NG) interneurons excites a variable form of tail-flip escape either voluntarily, during swimming, or in response to more gradual stimuli (Wine and Krasne, 1972; Reichert and Wine, 1982).

Changes in LG threshold can occur via the imposition or removal of "tonic inhibition" or by application of the neuromodulator serotonin (Glanzman and Krasne, 1983; Vu and Krasne, 1993; Vu et al., 1993), which also promotes a dominant posture and aggressive behavior in freely behaving crayfish (Livingstone et al., 1980; Huber and Delago, 1998). The modulatory effects of serotonin on LG depend on the social history and status of the animal; superfused serotonin enhances LG excitability in social isolates, in new and experienced dominant crayfish, and in new subordinate crayfish but reduces LG excitability in experienced subordinates (Yeh et al., 1996, 1997). Fighting also reduces LG excitability in experienced subordinates but produces only a slight reduction of LG excitability in experienced dominants (Krasne et al., 1997).

It is not known whether tonic inhibition is removed or serotonin is released in crayfish during fighting. If they are, the excitability of the LG circuit (and perhaps that of the MG and NG circuits as well) might be increased in isolates, in new dominants, and in new subordinates as they fight to determine a dominance hierarchy. Here we determine whether changes in the excitability of these circuits occur by recording their patterns of activation in freely behaving pairs of juvenile crayfish (Procambarus clarkii) as they interact to form a dominance hierarchy. By tracking the occurrence of each tail-flip behavior in two crayfish as one becomes dominant and the other subordinate, we can gain insight into how shifts in the thresholds of an ensemble of circuits can produce coherent new patterns of social behavior.

We have recorded the activation of each escape circuit in freely 
behaving juvenile crayfish by recording the tail-flip behavior and the associated change in the electric field around the animal. Activation of each tail-flip circuit creates a distinct electrical field potential pattern in the water surrounding the animal (Fricke, 1984, 1986; Beall et al., 1990; Featherstone et al., 1991) (L. Finley and D. Macmillan, personal communication). We used the tailflip behaviors and corresponding field potentials to identify activation of each tail-flip circuit in each member of a pair of freely behaving crayfish as they fought to determine their relative social status. Field potential recordings allow the natural activation of several neural circuits to be monitored during agonistic interactions that might be altered by leads from implanted electrodes. During the study, we identified a fourth type of tail-flip behavior that occurs during agonistic interactions between crayfish, and we describe it here for the first time. This behavior, labeled "offensive" tail flipping (OT), plays a prominent role in deciding relative social status.

\section{MATERIALS AND METHODS}

Sixteen juvenile crayfish (P. clarkii; $2.2-3.0 \mathrm{~cm}$ ) of both sexes that had been raised individually in isolation since becoming free-swimming $(>4$ months) were used throughout this study. Extracellular nerve and muscle potentials were recorded with a bipolar pair of electrodes implanted on the abdominal ventral nerve cord. Wire leads from the ventral cord electrodes were fixed to the carapace by superglue and connected to a differential amplifier (A-M Systems). Amplified $(1000 \times)$ signals were displayed on an oscilloscope, digitized at $6.7 \mathrm{kHz}$, and recorded in a personal computer with Axoscope (Axon Instruments). Field potentials from the aquarium bath were recorded with a second pair of copper wire electrodes ( $1 \mathrm{~mm}$ outer diameter, insulated except at the tips) placed at either end of the $9.5 \mathrm{~cm}$ (length) by $1.5 \mathrm{~cm}$ (width) by $5.5 \mathrm{~cm}$ (height) aquarium (Fig. 1A). These potentials were similarly amplified, displayed, and recorded. The recorded signals from the implanted and bath electrodes were similar in amplitude in part because the small aquarium size limited spread of the electric field away from the animal. The aquarium was filled with deionized water to a depth of $5.5 \mathrm{~cm}$, and the bottom was covered with gravel to facilitate walking. Sharp taps delivered by a handheld probe to the abdomen evoked an escape tail flip mediated by the LG interneurons, whereas taps delivered to the cephalothorax evoked a tail flip triggered by the MG interneurons (Wine and Krasne, 1972). Gentle pushes of the probe on the carapace evoked tail flips triggered by NG circuitry (Fig. 1B). A pair of bipolar electrodes at the tip of the probe established the time of contact with the animal by the sharp change in impedance between the electrodes. The behavior of the animal was recorded simultaneously with the field potentials by high-speed videography (5 msec/frame; JC Labs, San Mateo, CA). A mirror reflection of the oscilloscope traces in the top half of each video frame was used to align the temporal sequence of digitized field potentials with the behavior.

Video recordings were used alone to identify three behavior patterns (attack, approach, and retreat) (Issa et al., 1999), whereas field potentials and video recordings were used to identify and distinguish four different forms of tail flip (LG, MG, NG, and OT). NG tail flips were further divided into those that initiate an escape (NG) and those that constitute swimming (Swim) by occurring repetitively after an initial LG, MG, or NG tail flip. Attacks were defined [according to Issa et al. (1999)] as sudden movements of one animal toward another that led to physical contact and a response (one of the defined behavior patterns or tail flips) by the other animal. Approaches were defined as movements of one animal toward the other that failed to lead to contact but did provoke a response by the other animal. Retreats were locomotor movements of one animal away from the other in response to an attack or approach. Escapes are LG, MG, or NG tail flips that carry one animal rapidly away from the other, usually in response to an attack or approach. OTs are defined below. The animal that initiated most of the aggressive behaviors (attacks, approaches, or OTs) during the $30 \mathrm{~min}$ period of interaction was identified as the dominant, whereas the animal that initiated most of the defensive behaviors (retreat or escape) was the subordinate (Issa et al., 1999).

\section{RESULTS}

\section{Comparison of recordings from the aquarium electrodes and implanted electrodes}

Comparison of the amplified signals from the aquarium electrodes and the implanted electrodes revealed very similar electrical potential waveforms (Beall et al., 1990) (Fig. 2). In both the implanted and bath recordings, action potentials produced in the LG and MG neurons were immediately followed (after $1.4 \pm 0.1$ msec, mean $\pm \mathrm{SD}$ ) by a much larger phasic potential that is attributable to the synchronous excitation of the segmental motor giant (MoG) motor neurons and the fast flexor (FF) muscle fibers they excite (Fig. 2A,B) (Wine and Krasne, 1982). The phasic MoG potential was followed by a series of lower-amplitude oscillations that result from excitation of the FF muscle by the nongiant FF motor neurons (Heitler and Edwards, 1998). The NG tail-flip potentials lacked both the giant neuron action potential and the MoG potential but did display the lower-amplitude potential oscillations indicative of FF motor neuron excitation (Fig. 2C).

To determine whether the field potentials recorded from unimplanted, freely behaving animals were the same as those recorded from implanted animals, potentials evoked during each of the three types of tail flip were recorded five times in each of 16 unimplanted crayfish. There were no qualitative differences between the field potentials recorded from unimplanted animals and the corresponding potentials from implanted animals.

Each type of field potential in the unimplanted animals had a distinct amplitude and duration. The mean peak-to-peak amplitude of the MoG potential $(3.4 \pm 1.2 \mathrm{mV}$, mean $\pm \mathrm{SD})$ evoked by an MG spike was significantly greater $(p<0.05$, Friedman test of repeated measurements on ranks) than the MoG potential evoked by LG $(2.3 \pm 0.8 \mathrm{mV})$ or the largest potential evoked by $\mathrm{NG}(1.4 \pm 0.7 \mathrm{mV})$. However, the duration of the MoG potential evoked by LG $(1.9 \pm 0.4 \mathrm{msec}$, mean $\pm \mathrm{SD})$ was significantly longer than that evoked by MG $(1.4 \pm 0.1 \mathrm{msec})$. The duration of the largest biphasic NG potential $(2.6 \pm 0.5 \mathrm{msec})$ was significantly longer than either of the MoG potentials $(p<0.01$, Friedman test of repeated measurements on ranks). The mean durations $( \pm \mathrm{SD})$ of the entire LG- and MG-related field potentials were similar $(18.1 \pm 1.8$ and $15.0 \pm 1.0 \mathrm{msec}$, respectively), and both were shorter than the entire NG field potential $(23.8 \pm$ $2.4 \mathrm{msec}$ ). Although the mean values of each measurement of the different potentials were significantly different, their ranges overlapped.

\section{Categorization of tail flips during interactions between crayfish}

Categorization of a tail flip depends on the correlation between the high-speed video recording of the tail flip and the simultaneously recorded field potential. The field potentials were evoked only by tail flips, and animals were never seen to tail flip simultaneously, so that attribution of the field potential to a tailflipping animal is unambiguous.

NG tail flips can take any behavioral form, including those typical of LG and MG tail flips, but they have a much longer response latency than do LG or MG tail flips in response to an applied mechanical stimulus (Wine and Krasne, 1972). This measure was lacking in experiments in which two crayfish interact, and so identification of $\mathrm{NG}$ tail flips depended on the field potential. The NG field potential (Figs. 2C, 3A) lacked both the initial MoG potential and the immediately preceding giant neuron action potential that are characteristic of an MG or LG tail flip (Figs. $2 A, B, 3 B$ ) and so was readily identified. 

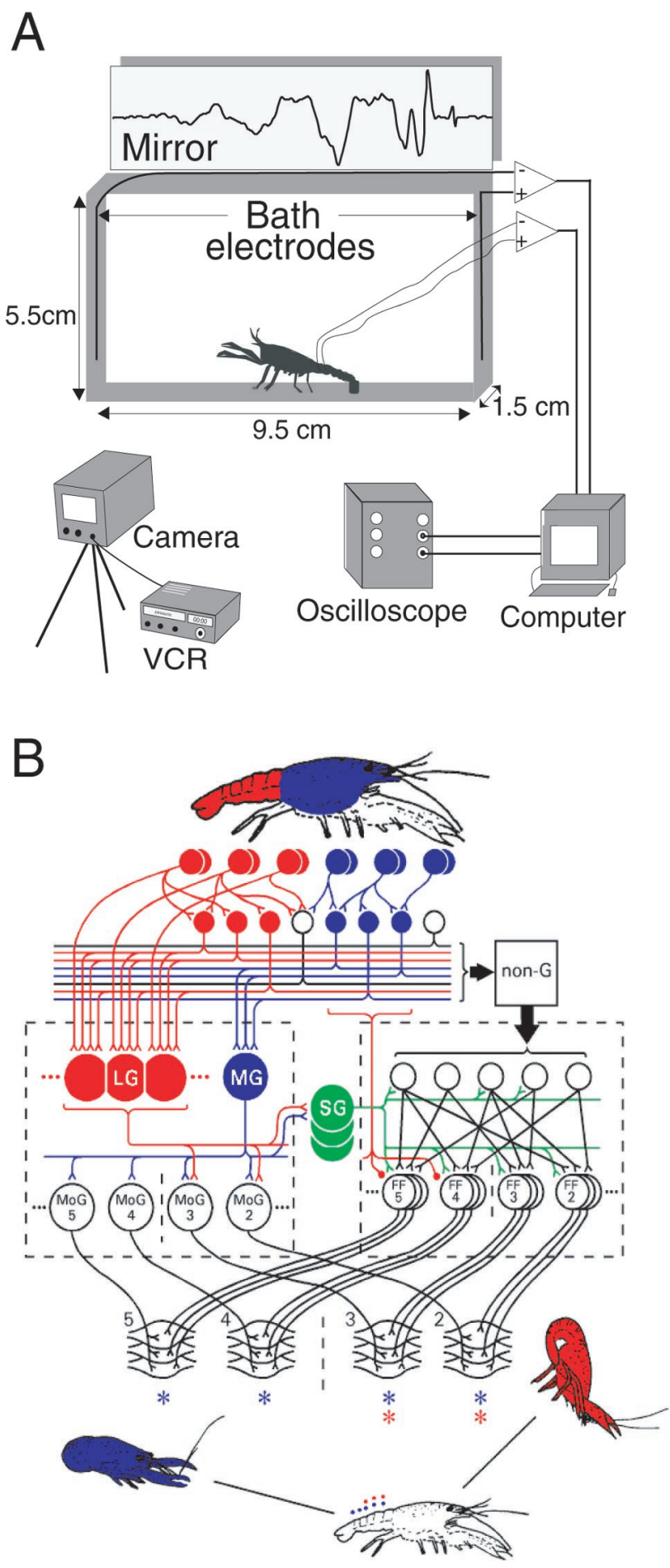

Figure 1. Experimental arrangement and the escape circuitry of crayfish. $A$, Experimental setup. Neural and muscular activity of one (control) or two (fighting) juvenile crayfish placed in a small test aquarium was recorded with implanted and bath electrodes or with bath electrodes alone. The reflected oscilloscope image of the signals was recorded in the top half of a high-speed video that also captured the tail-flip behavior of the animal(s) at $5 \mathrm{msec} /$ frame. $B$, Escape tail-flip circuitry of the crayfish. Primary mechanosensory afferents on the abdomen (top row of red circles) excite the LG neurons directly and through an intervening layer of mechanosensory interneurons (second row of red circles). The LG neurons in anterior segments excite motor giant motor neurons in the anterior part of the abdomen but not in the posterior part. The LGs also excite the segmental giant interneurons (green circles) in each segment, and the segmental giants then excite premotor interneurons and the set of fast
Although both LG and MG tail flips produce an initial MoG field potential, their tail-flip trajectories are readily distinguishable. Crayfish bend only the first three abdominal segments during LG tail flips, but bend all abdominal segments during MG tail flips, and so produce distinct trajectory angles for each type of giant tail flip (Wine and Krasne, 1972). These differences were apparent in the high-speed video recordings of the animals, which allowed a precise analysis of the movements of the animal during tail flipping. The tail-flip angles were measured in the sagittal plane of the animal, from the direction in which the animal faced, and $25 \mathrm{msec}$ after the first movement in each control experiment. Angles produced by LG $\left(98.9 \pm 7.7^{\circ}\right.$, mean $\left.\pm \mathrm{SD}\right)$ and $\mathrm{MG}$ $\left(155.3 \pm 7.6^{\circ}\right)$ tail flips in the control experiments were significantly different from each other $(p<0.01$, Wilcoxon signed rank test ) and were similar to the angles produced by the MG and LG tail flips reported previously (Wine and Krasne, 1972). The differences were maintained in giant-evoked tail flips produced during agonistic encounters between crayfish (LG, $98 \pm 0^{\circ}$; MG, $150.1 \pm 12.2^{\circ}$ ) and helped us to identify MG and LG tail flips produced during those encounters. The differences between the amplitudes and durations of the MoG potentials evoked by the LG and MG circuits described above provided additional criteria for distinguishing the tail flips produced by each circuit during agonistic encounters.

\section{Field potentials and tail-flip behaviors during agonistic interactions}

After a $1 \mathrm{~d}$ period of rest, the 16 juvenile crayfish used in the control experiments were paired for $30 \mathrm{~min}$ with another animal from the group of the same size and opposite sex. The two animals began a series of mutual agonistic encounters that soon resulted in one animal escaping and retreating in response to the attacks and approaches of the other.

The LG, MG, and NG tail flips that occurred during fighting were readily recognizable. They and the accompanying voltage records (Fig. 3A,B) were indistinguishable from the corresponding records obtained previously from the same animals when isolated and from the implanted animals (Fig. 2). The peak-topeak amplitudes and durations of the electrical field potentials were measured before and after pairing. There were no differences in the measurements of each tail flip between dominant and subordinate animals or within one animal before and after pairing. NG tail flips occurred both as the initial response to an attack (NG tail flips) and during swimming movements that followed each of the three types of escape (Swim tail flips).

A fourth, previously undescribed form of tail flip (offensive)

\section{$\leftarrow$}

flexor motor neurons in the anterior abdominal segments. These two sets of motor neurons excite fast flexor muscle in the anterior abdomen. Their contraction produces a rapid flexion around the thoracic-abdominal joint, which pitches the animal up and forward (bottom right). The MG neurons (blue circles) are excited by phasic visual and mechanosensory input to the cephalothorax and produce a rearward tail flip (blue; below left) by exciting motor giant and fast flexor motor neurons in all the abdominal segments. The NG neurons (box labeled non- $G$ ) are excited by less phasic stimuli delivered anywhere on the body surface. At much longer latency, they excite fast flexor motor neurons in several segments to produce a pattern of abdominal flexion that will carry the animal away from the stimulus source. $S G$, segmental giant; $M o G$, motor giant motor neurons; $F F$, fast flexor motor neurons. MoG and FF are shown for abdominal segments $2-5$ only. The asterisks refer to the FF muscles in abdominal segments 2-5 that are excited by the LG (red) and MG (blue) neurons. $V C R$, videocassette recorder. Reprinted from Edwards et al. (1999), with permission from Elsevier Science. 

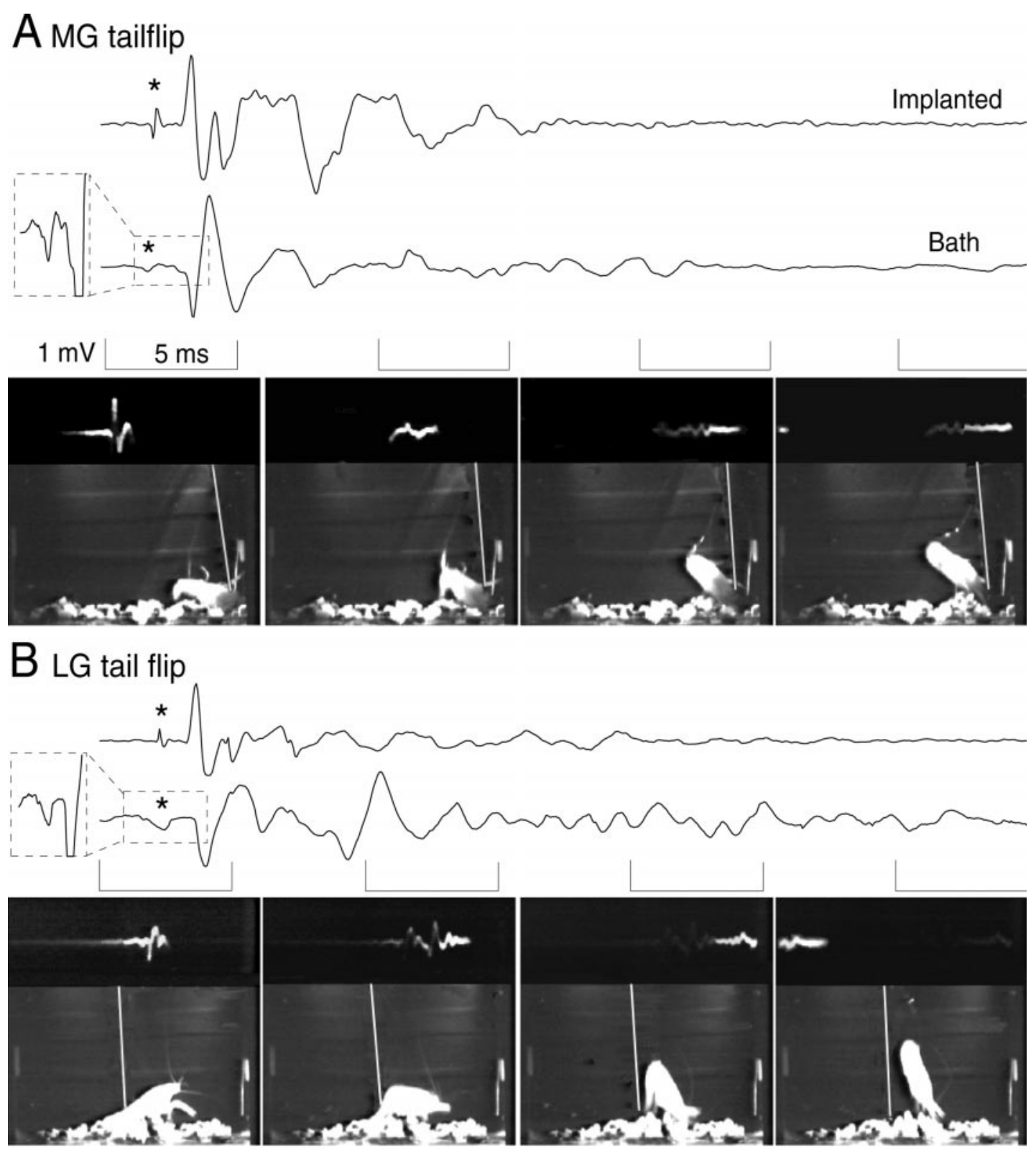

C NG tail flip

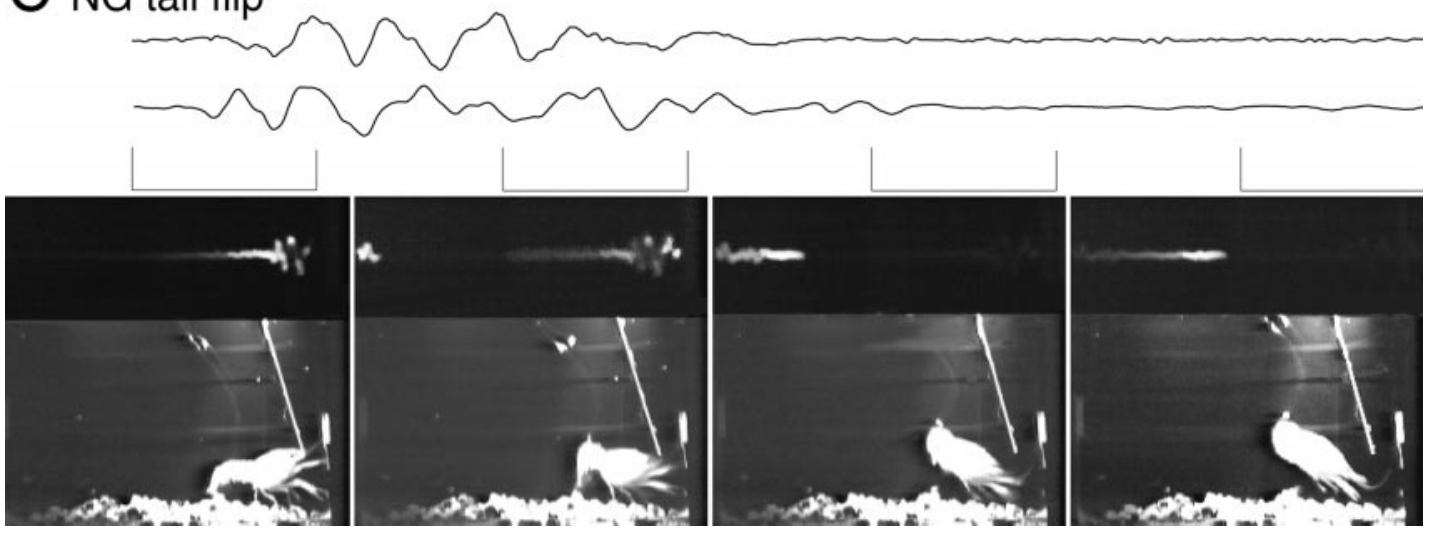

Figure 2. Digitized recordings from the implanted (top traces) and bath (bottom traces) electrodes with simultaneously recorded video frames of the tail-flip behavior of the animal. Each video frame also displays the reflected oscilloscope trace of the bath recording (at the top of each frame; the frames are each left-right reversed so that increasing time of the oscilloscope trace is from left to right), the animal, and the stimulus probe (white diagonal line). The bracketed periods of each trace correspond to the period of the frame displayed below. A, MG tail-flip response caused by a phasic probe stimulus to the front of the animal. The field potential includes the MG giant spike potential (* and magnified in the dashed box inset (Figure legend continues.) 
A

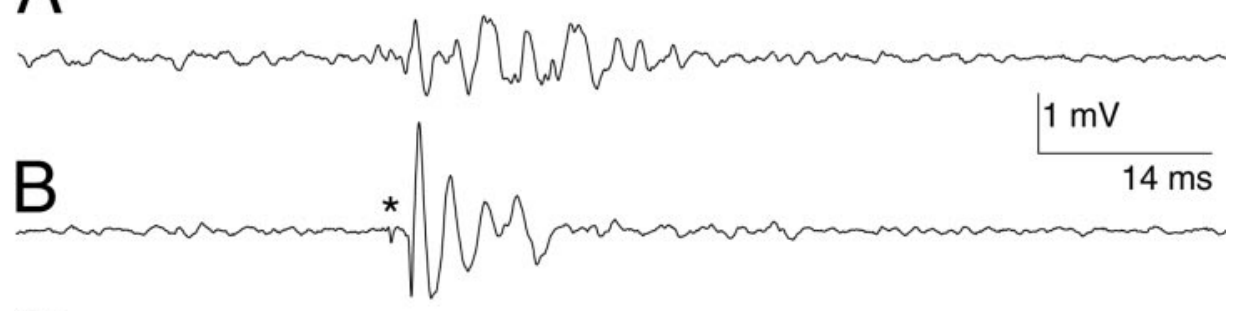

C



$0-5 \mathrm{~ms}$
0-5 20-25<smiles>[194Pb]</smiles>

60-65

80-85
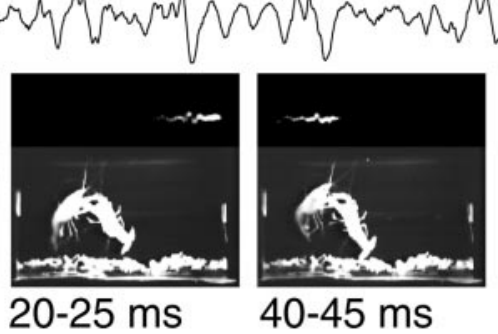

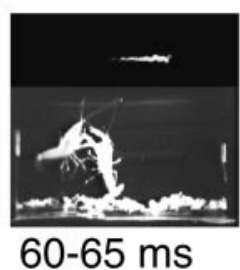

60-65 ms occurred only when the tail-flipping animal had a secure grip on its opponent (Fig. 3C). These OTs began with an abdominal extension followed by several $(2.9 \pm 1.4$, mean \pm SD) abdominal flexions and reextensions. The duration of the entire offensive potential $(74.1 \pm 5.3 \mathrm{msec})$ exceeded all other tail-flip potentials and correlated with a longer-duration abdominal movement (Fig. $3 C$ ). These characteristics make OTs readily distinguishable from NGs and giant neuron-evoked tail flips. The abdominal extensions were accompanied by a spread of the tailfan that was maintained during the abdominal flexion, which occurred primarily around the anterior abdominal segmental joints, while the posterior segments remained extended. This configuration helped to throw the animal up into the water column, above the opponent held in the grasp of the tail-flipping animal.

\section{Patterns of tail-flip circuit activation and behavior during dominance hierarchy formation}

The relative dominant and subordinate status of each pair was determined from counts of the numbers of attacks, approaches, escapes, and retreats that occurred throughout the interaction (Issa et al., 1999). The dominant animals were female in three of the eight pairs of juvenile crayfish and male in the others. No differences related to sex were observed in the behavior or recorded potentials.

Dominance hierarchy formation between two crayfish began with fighting that differed in intensity and duration among eight pairs of animals, from a pair of one-sided interactions with little fighting to a prolonged, intense fight that lasted almost $4.5 \mathrm{~min}$ before it was interrupted by the withdrawal of one animal. In six of eight pairs of animals, initial bouts of fighting included attacks, approaches, and OTs by both animals and few defensive behaviors such as retreats or escapes (Fig. 4). OTs usually occurred in alternating bouts, in which several tail flips made by one animal were followed by a series of OTs by the other. The future
Figure 3. Recordings from the bath electrodes and tail-flip behavior during fighting. $A$, NG tail-flip field potential. The field potential lacks the giant spike potential and the large $\mathrm{MoG}$ potential characteristic of a giant neuron response and consists only of FF muscle potentials in response to the FF motor neurons. $B$, MG circuit activation and tail-flip field potential. The MG spike potential (*) and the large, biphasic MoG potential can be seen, followed by the lower-amplitude response of the FF muscle to the FF motor neurons. $C$, Offensive tailflip field potential (top) and behavior (bottom). The signal is identified by its small amplitude and extremely long signal duration and results from a prolonged activation of the FF muscle by the FF motor neurons. No giant spike potential is recorded. Bracketed periods of the trace correspond in time with the sequence of frames. dominant animal always displayed the final bout of OTs before dominance status was decided, and it displayed more OTs than did the future subordinate. The status decision was apparent when a sudden change in the behavior of one animal, the future subordinate, occurred. The aggressive behavior of this animal, including attacks, approaches, and offensive tail flips, ceased, and defensive behavior, including a series of escapes, retreats, and swims, began (Fig. 4). The new dominant animal maintained its aggressive behavior after the decision and persisted with attacks and approaches. In three of the pairs the initial fight was decisive and produced a sharp switch from offensive to defensive behavior in one animal, while the other continued to behave offensively. This is illustrated by the ethogram of Figure $4 A$, in which the different behavioral events are displayed according to their time of occurrence (top) and according to their order of occurrence (bottom). The temporal display shows that for this pair, most of the activity occurred within the first $10 \mathrm{~min}$ of interaction. The bottom display shows that the decision of one animal to withdraw and cease offensive behavior was abrupt. The temporal display shows that the level of agonistic activity by both animals declined over the remaining part of the half hour. The ethograms of two other pairs of animals are similar (data not shown): an abrupt change in the behavior of one animal persists throughout the remainder of the $30 \mathrm{~min}$ interaction. In four other pairs the initial decision was incomplete: having switched from offensive to defensive behavior once, the new subordinate animal reengaged the new dominant with brief bouts of offensive behavior. An example is seen in Figure $4 B$, in which after an initial decision after 5 min of interaction, the new subordinate reengaged the new dominant with periodic approaches, offensive tail flips, and attacks. These were isolated events in all the pairs and did not change the balance of behavior between the animals.

The changes in behavior over time can be seen in the plots of

\section{$\leftarrow$}

(Figure legend continued.) to the left of the trace), the large, phasic MoG potential, and the lower-amplitude potentials produced by the FF motor neurons and FF muscles. $B$, LG tail-flip response caused by a phasic probe stimulus to the abdomen. As for MG, the LG field potential includes the LG spike potential (* and magnified in the dashed box inset), the MoG potential, and the FF motor neuron and FF muscle responses. $C$, NG tail-flip response to a nonphasic probe stimulus to the thorax. The field potential consists only of FF motor neuron and FF muscle potentials. No giant spike potential was recorded. 
Figure 4. Sequence of tail-flip circuits activated and behavior patterns displayed by two of the eight pairs of animals during the $30 \mathrm{~min}$ period of dominance hierarchy formation. Events are presented according to their time of occurrence (top) and in their order of occurrence (bottom). $X$ and $O$ symbols mark the behavior of the new dominant and subordinate animals, respectively. The dashed vertical lines give the approximate time of the dominance decision. OT, MG-evoked, NG-evoked, and Swim nongiant-evoked tail flips are activated. $A$, A pair in which the initial decision (dashed vertical line) was decisive. $B, \mathrm{~A}$ pair in which the new subordinate reengaged the new dominant at intervals after the initial decision (dashed vertical line).

Figure 5, where the frequencies of each behavior are expressed as the total number of occurrences in all animals in $5 \mathrm{~min}$ periods over the $30 \mathrm{~min}$ period of interaction. The period between their introduction and the onset of vigorous fighting differed among the pairs. This onset was marked by the first tail flip, whether an escape or an OT, which enabled the time series of responses from all eight pairs to be compared by aligning them along the time axis with the time of the first tail flip at time 0. Dominant and subordinate animals made similar numbers of attacks, approaches, and retreats during the period before that first tail flip (Fig. 5A). The greatest aggressive activity occurred during the first 5 min after the initial tail flip, when large numbers of attacks (45), approaches (20), and offensive tail flips (85) by the dominant animal evoked correspondingly high frequencies of retreats (21) and escape tail flips of all types (210) by the subordinate, the vast majority of which were NG and Swim tail flips (194). Dominant animals in all pairs produced few retreats (2) or escape (LG, MG, or NG) tail flips (24) within the first $5 \mathrm{~min}$ of vigorous interaction, whereas the subordinate produced few attacks (7), approaches (1), or offensive tail flips (36) during this period (Fig. 5). Both types of animals produced a small number of MG tail flips, with the greater number being produced by the subordinates (dominants, 11; subordinates, 16).

Both dominants and subordinates performed many fewer offensive tail flips (14 and 5, respectively) during the second $5 \mathrm{~min}$ period (Fig. $5 B$ ), after the decision had been made for most pairs. The drop in OTs reflects the absence of fighting in which the animals grapple each other. The dominant animals persisted in approaching (22) and attacking (27) the subordinates, which responded by retreating (21) and escaping (127). Only 5 of these escapes were of the more forceful MG type, reflecting the reduced level of aggressiveness of the dominant animals.


The level of aggressiveness of the dominant animals fell almost linearly to $\sim 15 \%$ of its initial level after $30 \mathrm{~min}$, as reflected in the decline in the numbers of attacks and approaches (Fig. 5). An increase in the number of attacks by the dominant animal in two pairs occurred in the fourth $5 \mathrm{~min}$ period $(15-20 \mathrm{~min})$ and accounts for the deviation from the downward trend in summed agonistic activity. The dominant member of one of those pairs also produced the increase in the number of OTs reported during that period (Fig. 5). The frequency of retreats and NG escapes (including Swim) by the subordinate fell in parallel with the decline in attacks and approaches by the dominant. MG tail flips occurred primarily during the first period of intense interaction, primarily in the subordinate animal. MG tail flips continued at a low level in both animals throughout their interaction. The only LG tail flip recorded in all pairs occurred when a dominant animal struck a subordinate on the abdomen during the second 5 min period.

The differences in the behavior of dominant and subordinate animals are made clear in Figure 6. Dominant animals made more attacks than did subordinates $(p<0.01$, Wilcoxon signed rank test) and more approaches $(p<0.02)$, more OTs $(p<0.04)$, fewer retreats $(p<0.02)$, fewer NG tail flips $(p<0.01)$, and fewer swim tail flips $(p<0.01)$ than did subordinate animals. No significant differences occurred in the number of MG tail flips made by dominant and subordinate animals.

\section{DISCUSSION}

\section{Field potential measurements and tail-flip circuit activation}

Field potential measurements have provided a means for distinguishing between giant neuron-evoked and NG-mediated tail flips in freely behaving crayfish (Beall et al., 1990). Together with 
A
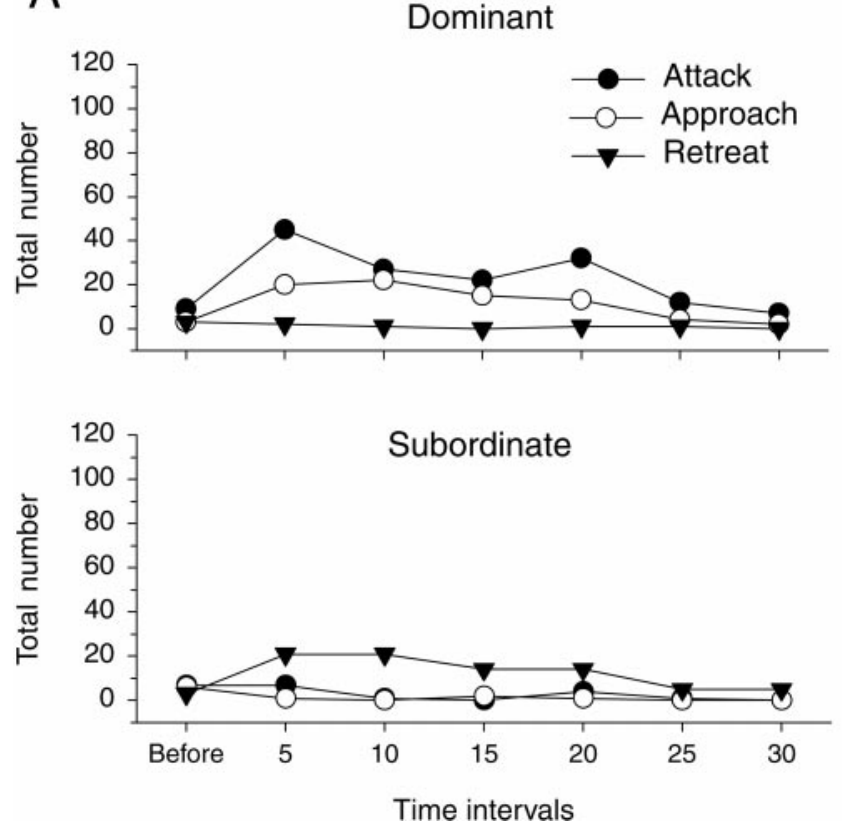

B
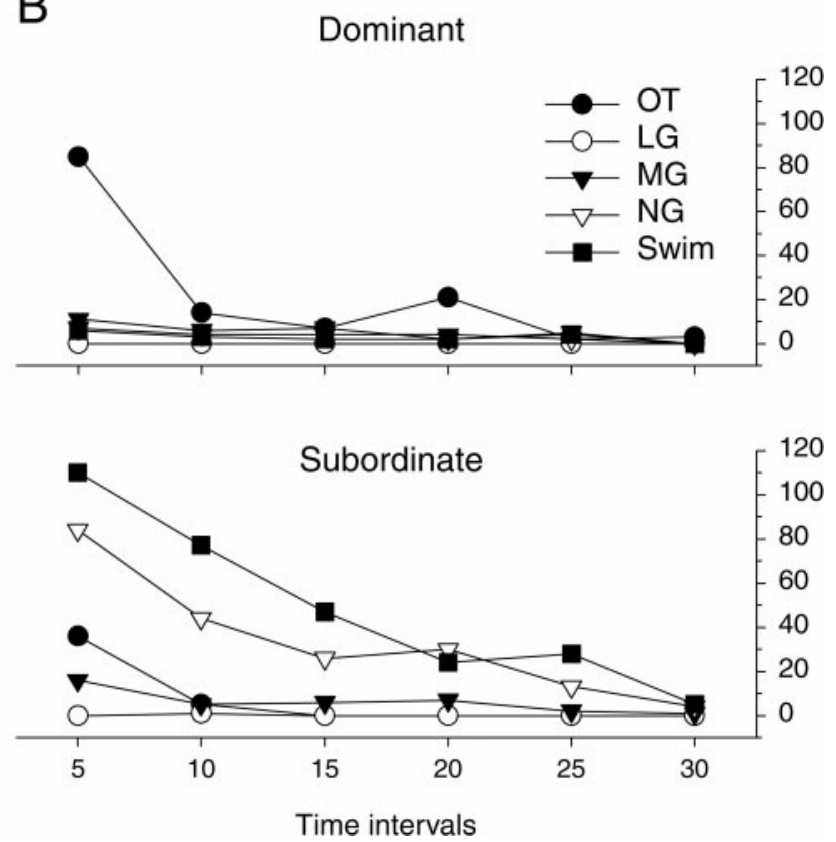

Figure 5. Patterns of offensive and defensive behavior during $30 \mathrm{~min}$ of interaction between eight pairs of unacquainted crayfish. Total numbers of events are shown for dominant (top) and subordinate (bottom) animals in all eight pairs in sequential 5 min periods. The first tail flip of each pair marks the beginning of the first 5 min period (i.e., time 0) for that pair; the sequence of periods of each pair is aligned with that mark. $A$, Attacks, approaches, and retreats. Before indicates behavioral events that occurred before the first tail flip. $B$, Different types of tail-flip behavior. The 5 min periods correspond to the similarly labeled periods in $A$.

an analysis of the form and trajectory of the tail-flip escape, this technique has enabled us to distinguish clearly the separate activation of three circuits, LG, MG, and NG, that govern tail-flip escape behavior in P. clarkii. Another application of the technique with the Australian crayfish Cherax destructor has led to a similar conclusion (Finley and Macmillan, personal communication). The technique has enabled us to determine the natural patterns of activation of these tail-flip circuits during agonistic

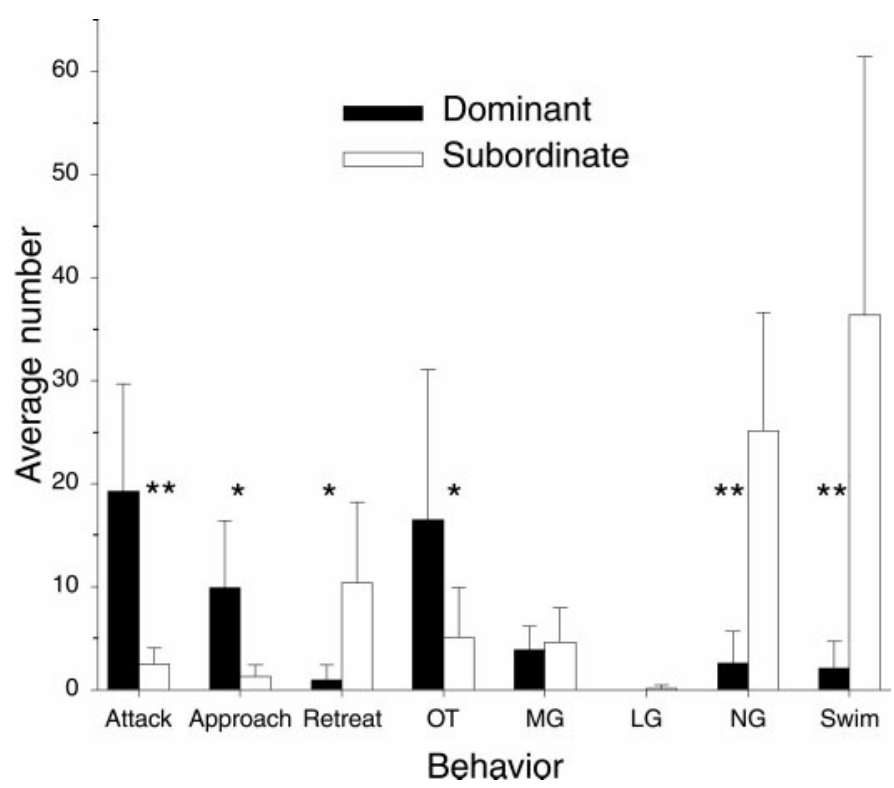

Figure 6. The average numbers of different agonistic behavior patterns ( \pm SD) performed by dominant and subordinate animals in eight pairs during 30 min of interaction $(* *$, significantly different with $p<0.01 ; *$, significantly different with $p<0.05$; Wilcoxon signed rank test). interactions between freely behaving animals that led to formation of a social dominance hierarchy. It has also helped us to identify a new tail-flipping behavior used offensively during agonistic interactions.

The use of field potential recordings to identify patterns of tail-flip circuit activation takes advantage of the large size of the giant fibers and the specific circuit arrangement via which they trigger a tail flip. The large phasic potential that follows the LG or MG spike (Fig. $2 A, B$ ) results from the almost synchronous excitation of the set of abdominal MoG motor neurons and the subsequent almost synchronous excitation of the segmental FF muscles that the MoGs excite (Heitler and Darrig, 1986; Beall et al., 1990; Fraser and Heitler, 1991; Heitler and Fraser, 1993; Heitler and Edwards, 1998; Edwards et al., 1999). The MoG potential evoked by MG excitation is larger than that produced by LG because MG excites MoG motor neurons and FF muscles in all abdominal segments, whereas LG excites MoGs and FF muscles only in the most rostral segments (Miller et al., 1985; Edwards et al., 1999). In experiments with the Australian crayfish $C$. destructor, the initial phasic potentials produced by LG and MG circuits had opposite polarity (Finley and Macmillan, personal communication). This was not the case with $P$. clarkii, perhaps because of differences between the animals or between the experimental arrangements.

No large impulse appears during NG activation in either Procambarus or Cherax (Finley and Macmillan, personal communication) because the NG circuit makes no use of the MoG motor neurons. Instead, the NG circuit excites a set of nongiant FF motor neurons in each abdominal segment according to the needed pattern of abdominal flexion. The FF motor neurons excite subsets of FF muscles, and this pattern of muscle excitation accounts for the longer, lower-amplitude field potentials recorded during an NG tail flip. The similar pattern of low-amplitude field 
potentials that follows the initial phasic MoG response when LG or MG is activated also results from excitation of the FF motor neurons and their excitation of the FF muscle. Whereas the MoG motor neurons are excited by en passant synapses made directly by the LG and MG axons (Furshpan and Potter, 1959), the FF motor neurons are excited indirectly by LG and MG via a disynaptic pathway that produces a delay in the response (Edwards et al., 1999). The subsequent patterns of FF muscle excitation account for the prolonged field potential that follows each large MoG-related response.

Offensive tail flips may be a variant of the NG escape tail flip but are more likely to be produced by a circuit that is distinct from the three escape circuits. The hallmark of the OT is the slow abdominal flexion performed as the animal grasps its opponent. The NG tail flip is much faster but might conceivably be slowed if the animal were to perform it while dragging a heavy load. The animal drags its opponent during an OT, but the direction of the tail flip is initially upward and perpendicular to the axis of the connection between the animals. The perpendicular direction of the tail flip relative to the direction of the inertial force of the load (i.e., the opponent) suggests that the force developed by the abdominal flexion should initially be primarily unaffected by the load of the opponent. As a result, one would expect that the initial flexion of an NG tail flip would be rapid until the load slows it down. This is not what happens. An OT begins with an extension that is immediately followed by a slow flexion that throws the animal upward. This result suggests that the OT differs categorically from the NG tail flip.

\section{Sequences of behavior that lead to hierarchy formation}

Previous studies have shown how the expression of agonistic behaviors, including approaches, attacks, retreats, and escapes, changes over 2 weeks after the formation of a dominance hierarchy (Issa et al., 1999). An initial period of vigorous attacks and approaches by the new dominant animal and retreats and escapes by the new subordinates was followed by a significant reduction in agonistic activity as each of the animals became used to their new status. Here we have tracked the sequence of behavior displayed by two animals during initial encounters that led to formation of a dominance hierarchy and determined how the different patterns of tail-flip behavior contribute to hierarchy formation.

Changes in the pattern of tail-flip circuit activation underlie part of the behavioral change that occurs as one animal becomes dominant and the other subordinate. These changes hinge on a decision point when the prospective subordinate switches from offensive tail flipping and fighting to initiating repeated $\mathrm{MG}$ and NG escapes. The change in circuit activation appears to result from corresponding changes in the thresholds for excitation of the different circuits (Krasne et al., 1997). Before the decision point, both animals made attacks and approaches and performed offensive tail flips when grappling with the opponent, although the prospective dominant was the more active. During this time, both animals performed very few retreats or escapes. After the decision point, the new dominant continued to behave aggressively, whereas the subordinate switched from aggressive to defensive behavior. The dominant maintained the frequency of attacks during the initial period after the decision but performed fewer approaches and OTs. The subordinate ceased offensive behavior and began performing repeated tail-flip escapes, primarily those mediated by NG circuits but also those mediated by MG circuitry.
The LG circuit was excited only once, by a direct attack on the abdomen of the subordinate.

\section{The use of tail-flip circuits during hierarchy formation}

These experiments have changed our view of the three different escape circuits and the ways in which the animal uses them. The LG and MG have been seen as escape command neurons that trigger rapid, reflexive escapes upward or backward in response to rearward or frontward attacks, respectively (Wiersma, 1947; Wine and Krasne, 1972). LG and MG tail flips require strong, phasic stimuli when the animal is at rest (Wine and Krasne, 1982), although the precise stimulus threshold of an LG tail flip can be affected by descending inputs, applied serotonin, reafference, and ongoing behaviors, including fighting (Kennedy et al., 1980; Glanzman and Krasne, 1983; Beall et al., 1990; Krasne et al., 1990, 1997; Yeh et al., 1996, 1997). The NG circuits were seen to trigger longer-latency tail flips in response to more gradual stimuli, to control swimming movements after an initial tail flip, and to trigger escape tail flips in long-term subordinates (Krasne and Wine, 1984).

The current experiments make clear that stimulus conditions necessary for the MG and NG tail flips change significantly in new subordinate animals, whereas the adequate stimulus for LG appears not to change. Both the MG and NG circuits appear to become more excitable after dominance has been decided. Many of these MG tail flips cannot be readily attributed to any stimulus other than the nearby presence of the dominant animal, suggesting that the MG threshold decreases significantly during fighting and may even become "voluntary." Subordinates performed 20 of the 29 voluntary tail flips seen in all eight pairs of animals, and they performed more of them than did dominants in six pairs, suggesting that the threshold for activating an MG tail flip is lower in subordinates than in dominants. The greatest change in apparent threshold was experienced by NG escape behavior, which was a rare event before the status decision was made and quickly became the predominant behavior of the subordinate animal afterward.

Previous studies suggested that serotonin may be released during fighting between crayfish, where it promotes an aggressive posture, reduces the motivation of a subordinate to retreat (Livingstone et al., 1980; Kravitz, 1988; Huber and Delago, 1998), and facilitates the excitability of LG in new dominant and subordinate crayfish (Yeh et al., 1996, 1997). Contrary to our expectation, however, the LG escape circuit did not appear to become more excitable during a confrontation and fighting between two isolate crayfish or between new dominant or subordinate crayfish after the decision of relative social status. Indeed, in the present experiments, LG-mediated escape occurred only once, in response to the same sort of phasic abdominal stimulus that triggers an LG escape in a quietly resting animal. However, the lack of LG tail flips may be an artifact of the confined space of the small, narrow aquarium used in these experiments, in which the animals normally occupied positions facing each other. Informal observation of crayfish in a larger aquarium suggests that the body orientation, position, and behavior of crayfish are governed by the direction and distance of possible threats, including larger dominant animals. LG tail flips may occur more frequently during interactions in a larger, object-rich arena, in which potential threats are more numerous and the direction of possible attack is less certain. A similar, context-sensitive change in LG threshold is seen in crayfish that acquire a small portable piece of food (the threshold drops) or a large immovable piece of food (the thresh- 
old rises) (Bellman and Krasne, 1983; Krasne and Lee, 1988). Such changes in threshold may reflect the imposition or removal of tonic inhibition, which has been shown to produce momentary variation in the excitability of the LG neuron ( $\mathrm{Vu}$ and Krasne, 1993; Vu et al., 1993).

Offensive tail flipping has not been described previously but appears to play an important role in dominance hierarchy formation between size-matched crayfish. During initial fighting, crayfish appear to use bouts of repeated OTs to drag their opponent and gain a position above it. The alternation in bouts of OTs between two animals as they grapple suggests that each is trying to demonstrate its size and strength to the other. The slow rate of abdominal flexion relative to escape movements is consistent with this suggestion in that OTs are not used to injure or dismember an opponent. The future dominant displays more OTs in each bout, more bouts, and the last bout before the status decision. The decision often followed the last bout quickly, as the subordinate displayed a series of NG tail flips that signaled its defeat. We conclude that the OTs appear to provide a means for each crayfish to assess its strength relative to its opponent and to reach a status decision without suffering injury.

The neural mechanisms that account for the coordinated changes in circuit thresholds associated with the change in status are unknown but may include the tonic inhibitory mechanisms and serotonergic modulation that have been found previously to affect the LG threshold (Vu and Krasne, 1993; Yeh et al., 1997). These mechanisms must function in an almost step-like manner across many circuits to affect the adaptive change in behavioral state associated with a change in dominance status.

\section{REFERENCES}

Beall SP, Langley DJ, Edwards DH (1990) Inhibition of escape tailflip in crayfish during backward walking and the defense posture. J Exp Biol 152:577-582.

Bellman KL, Krasne FB (1983) Adaptive complexity of interactions between feeding and escape in crayfish. Science 221:779-781.

Bovbjerg RV (1953) Dominance order in the crayfish Oconectes virilis (Hagen). Physiol Zool 26:173-178.

Bruski CA, Dunham DW (1987) The importance of vision in agonistic communication of the crayfish Orconectes rusticus. I: An analysis of bout dynamics. Behaviour 103:83-107.

Edwards DH, Heitler WJ, Krasne FB (1999) Fifty years of a command neuron: the neurobiology of escape behavior in the crayfish. Trends Neurosci 22:153-161.

Featherstone D, Drewes CD, Coats JR (1991) Noninvasive detection of electrical events during the startle response in larval medaka. J Exp Biol 158:583-589.

Figler MH, Finkelstein JE, Twum M, Peeke HVS (1995) Intruding male red swamp crayfish, Procambarus clarkii, immediately dominate members of established communities of smaller, mixed-sexed conspecifics. Aggressive Behav 21:225-236.

Fraser K, Heitler WJ (1991) Photoinactivation of the crayfish segmental giant neuron reveals a direct giant-fiber to fast-flexor connection with a chemical component. J Neurosci 11:59-71.

Fricke RA (1984) Development of habituation in the crayfish due to selective weakening of electrical synapses. Brain Res 322:139-143.

Fricke RA (1986) Structure-function considerations in the developmental expression of crayfish behavioral plasticity. IEEE Trans Syst Man Cybern 1:513-518.
Furshpan EJ, Potter DD (1959) Transmission at the giant motor synapses of the crayfish. J Physiol (Lond) 145:289-325.

Glanzman DL, Krasne FB (1983) Serotonin and octopamine have opposite modulatory effects on the crayfish's lateral giant escape reaction. J Neurosci 3:2263-2269.

Heitler WJ, Darrig S (1986) The segmental giant neurone of the signal crayfish, Pacifastacus leniusculus, and its interactions with abdominal fast flexor and swimmeret motor neurons. J Exp Biol 121:55-75.

Heitler WJ, Edwards DH (1998) Effect of temperature on a voltagesensitive electrical synapse in crayfish. J Exp Biol 201:503-513.

Heitler WJ, Fraser K (1993) Thoracic connections between crayfish giant fibres and motor giant neurones reverse abdominal pattern. J Exp Biol 181:329-333.

Huber R, Delago A (1998) Serotonin alters decisions to withdraw in fighting crayfish, Astacus astacus: the motivational concept revisited. J Comp Physiol [A] 182:573-583.

Huber R, Kravitz EA (1995) A quantitative analysis of agonistic behavior in juvenile American lobsters (Homarus americanus L.). Brain Behav Evol 46:72-83.

Issa FA, Adamson DJ, Edwards DH (1999) Dominance hierarchy formation in juvenile crayfish, Procambarus clarkii. J Exp Biol 202:3497-3506.

Kennedy D, McVittie J, Calabrese R, Fricke RA, Craelius W, Chiapella P (1980) Inhibition of mechanosensory interneurons in the crayfish. I. Presynaptic inhibition from giant fibers. J Neurophysiol 43:1495-1509.

Krasne FB, Lee SC (1988) Response-dedicated trigger neurons as control points for behavioral actions: selective inhibition of lateral giant command neurons during feeding in crayfish. J Neurosci 8:3703-3712.

Krasne FB, Wine JJ (1984) The production of crayfish tailflip escape responses. In: Neural mechanisms of startle behavior (Eaton RC, ed), pp 179-211. New York: Plenum.

Krasne FB, Vu ET, Lee SC (1990) The excitability of the crayfish lateral giant escape reaction: inhibitory control of the lateral giant dendrites. In: Frontiers in crustacean neurobiology (Wiese K, Krenz W-D, Tautz J, Reichert H, Mulloney B, eds), pp 316-322. Berlin: Birkhauser.

Krasne FB, Shamsian A, Kulkami R (1997) Altered excitability of the crayfish lateral giant escape reflex during agonistic encounters. J Neurosci 17:709-716.

Kravitz EA (1988) Hormonal control of behavior: amines and the biasing of behavioral output in lobsters. Science 241:1775-1781.

Livingstone MS, Harris-Warrick RM, Kravitz EA (1980) Serotonin and octopamine produce opposite postures in lobsters. Science 208:76-79.

Lowe ME (1956) Dominance-subordinance relationships in the crayfish Cambarellus shufeldtii. Tulane Stud Zool 4:139-170.

Miller LA, Hagiwara G, Wine JJ (1985) Segmental differences in pathways between crayfish giant axons and fast flexor motoneurons. J Neurophysiol 53:252-265.

Pavey CR, Fielder DR (1996) The influence of size differential on agonistic behaviour in the freshwater crayfish, Cherax cuspidatus (Decapoda: Parastacidae). J Zool 238:445-457.

Reichert H, Wine JJ (1982) Neural mechanisms for serial order in a stereotyped behaviour sequence. Nature 296:86-87.

Vu ET, Krasne FB (1993) Crayfish tonic inhibition: prolonged modulation of behavioral excitability by classical GABAergic inhibition. J Neurosci 13:4394-4402.

Vu ET, Lee SC, Krasne FB (1993) The mechanism of tonic inhibition of crayfish escape behavior: distal inhibition and its functional significance. J Neurosci 13:4379-4393.

Wiersma CAG (1947) Giant nerve fiber system of the crayfish: a contribution to comparative physiology of synapse. J Neurophysiol 10:23-38.

Wilson EO (1975) Sociobiology. Cambridge, MA: Harvard UP.

Wine JJ, Krasne FB (1972) The organization of escape behavior in the crayfish. J Exp Biol 56:1-18.

Wine JJ, Krasne FB (1982) The cellular organization of crayfish escape behavior. In: The biology of crustacea (Sandeman DC, Atwood HL, eds), pp 241-292. New York: Academic.

Yeh SR, Fricke RA, Edwards DH (1996) The effect of social experience on serotonergic modulation of the escape circuit of crayfish. Science 271:366-369.

Yeh SR, Musolf BE, Edwards DH (1997) Neuronal adaptations to changes in the social dominance status of crayfish. J Neurosci 17:697708 . 